\title{
The Effects and Role of Polyvinylpyrrolidone on the Size and Phase Composition of Iron Oxide Nanoparticles Prepared by a Modified Sol-Gel Method
}

\author{
Marcela F. Silva, ${ }^{1}$ Luiz A. S. de Oliveira, ${ }^{2}$ Mariani A. Ciciliati, ${ }^{1}$ \\ Michele K. Lima, ${ }^{1}$ Flávio F. Ivashita, ${ }^{3}$ Daniela M. Fernandes de Oliveira, ${ }^{1}$ \\ Ana Adelina W. Hechenleitner, ${ }^{1}$ and Edgardo A. G. Pineda ${ }^{1}$ \\ ${ }^{1}$ Departamento de Química, Universidade Estadual de Maringá, 87020-900 Maringá, PR, Brazil \\ ${ }^{2}$ Núcleo Multidisciplinar de Pesquisas em Nanotecnologia (NUMPEX-NANO), Universidade Federal do Rio de Janeiro, \\ Campus Xerém, 25245-390 Duque de Caxias, RJ, Brazil \\ ${ }^{3}$ Departamento de Física, Universidade Estadual de Maringá, 87020-900 Maringá, PR, Brazil
}

Correspondence should be addressed to Marcela F. Silva; celafs@gmail.com

Received 24 January 2017; Accepted 23 April 2017; Published 17 May 2017

Academic Editor: Andrea Falqui

Copyright (C) 2017 Marcela F. Silva et al. This is an open access article distributed under the Creative Commons Attribution License, which permits unrestricted use, distribution, and reproduction in any medium, provided the original work is properly cited.

$\mathrm{Fe}_{2} \mathrm{O}_{3}$ nanoparticles (as maghemite and hematite mixtures) were prepared using adapted sol-gel method from a polyvinylpyrrolidone (PVP) aqueous solution in various $\mathrm{Fe}^{3+}$ : PVP monomer ratios. Analysis of X-ray diffraction was obtained to evaluate the crystalline state, average crystallite size, and composition of iron oxide phases. The morphology and average nanoparticles size were evaluated by electronic transmission microscopy. Magnetic properties of iron oxide were analyzed at low and room temperatures. Optical characteristics were evaluated by UV-Vis photoacoustic spectroscopy and the Mössbauer spectrum was obtained in order to evaluate subtle changes in the nuclear environment of the iron atoms.

\section{Introduction}

The last two decades have seen a significant growth in the study of nanomaterials such as iron oxide nanoparticles. The interest in research related to iron oxides nanoparticles, like magnetite $\left(\mathrm{Fe}_{3} \mathrm{O}_{4}\right)$, maghemite $\left(\gamma-\mathrm{Fe}_{2} \mathrm{O}_{3}\right)$, and hematite $\left(\alpha-\mathrm{Fe}_{2} \mathrm{O}_{3}\right)$ has been expanded in significate manner at present as a result of their characteristics as magnetism and optical activity and low cost and to their potential applications as catalysts and adsorbent for natural and synthetic micropollutants [1, 2], in Li batteries [3], and in some medical and pharmaceutical uses [4-6]. Moreover, they have attracted much attention because of their surface effect (large surface-area-to-volume ratio) that leads to novel physical and chemical properties and, consequently, the synthesis of nanostructured iron oxides particles has been studied [7].
Various methods have been reported for preparing nanoparticles, for example, sol-gel methods [8,9], ultrasonicassisted methods [10], thermal and hydrothermal pyrolysis [11], combustion [12], and microemulsion [13]. However, these methods present some disadvantages such as the control of $\mathrm{pH}$, moisture, and temperature of the medium, as well as the long time required to obtain the final materials and the use of expensive equipment and organic solvents, which are harmful to the environment [14-16]. To conquer the disadvantages related to previously cited methods, polymeric capping substances are used to protect the nanoparticles and avoid the aggregation. The characteristics of iron oxide can be changed by regulating the diameter and crystallization form. So, to control the rise of nanostructured $\mathrm{Fe}_{2} \mathrm{O}_{3}$, polymeric molecules like polyvinyl alcohol (PVA) and polyvinylpyrrolidone (PVP) are included in the time of the obtaining procedure to cover the nanoparticles [4, 17-22]. 
This study depicts the obtainment of iron oxide nanostructured particles by a uncomplicated adapted sol-gel synthesis. In this method, only aqueous solutions were used and a double of steps summarize brief precipitation, thermal decomposition, and incineration. Using a synthesized polymer (PVA), polymerization step is excluded, leading to a more simple mechanism without $\mathrm{pH}$ control and, also, iron sources different from alkoxides represent lower cost in comparison to traditional method. We previously reported the obtainment of other oxides such as nickel, zinc, cooper, iron, and the mixture of these oxides using the same procedure, with PVA as the capping agent $[9,12,18,22]$. This paper aims to study the influence of the amount of PVP on the size, crystalline structure, and properties of the obtained material. Thus, the fundamental question that it attempts to comprehend is how and to what extent the PVP capping agent improves the efficiency of iron oxide nanoparticles synthesized by this modified sol-gel method.

The synthesized nanoparticles were characterized by Fourier transform infrared spectroscopy (FTIR), X-ray powder diffraction (XRD), transmission electron microscopy (TEM), magnetic measurements (magnetization versus temperature in the range of $5-300 \mathrm{~K}$ and magnetization versus applied magnetic field), and Mössbauer spectroscopy.

\section{Experimental}

2.1. Materials. Materials were ferric nitrate $\left(\mathrm{Fe}\left(\mathrm{NO}_{3}\right)_{3} \cdot 9 \mathrm{H}_{2} \mathrm{O}\right)$ (Vetec, Brazil) and polyvinylpyrrolidone (PVP; MW $1,300,000)$ (Aldrich, USA).

2.2. Synthesis. Nanostructured $\mathrm{Fe}_{2} \mathrm{O}_{3}$ was synthesized using an adapted sol-gel synthesis [4, 17]. PVP $(10 \% \mathrm{w} / \mathrm{v})$ in aqueous solution and saturated ferric nitrate solutions were separately prepared and then mixed at $\mathrm{Fe}^{3+}:$ PVP monomeric unit ratios of $1: 6,1: 12,1: 18$, and $1: 24$ and the samples were, respectively, named as P6, P12, P18, and P24. The mixtures were stirred for $120 \mathrm{~min}$ at $25^{\circ} \mathrm{C}$. Afterwards, they were submitted to warm with hard hustle until wholly dehydration. The organic matter was burned at $423 \mathrm{~K}$ and nanoparticles were obtained upon calcination at $620 \mathrm{~K}$ under air atmosphere during $240 \mathrm{~min}$.

2.3. Analysis. The nanostructured $\mathrm{Fe}_{2} \mathrm{O}_{3}$ were evaluated using infrared spectroscopy (FTIR) with an FTIR-BOMEM100 Spectrometer $(\mathrm{KBr}$ pellets $1 / 100 \mathrm{w} / \mathrm{w})$. The X-ray measurements were obtained by a Siemens D-5000 powder diffractometer using monochromated $\mathrm{Cu}-\mathrm{K} \alpha$ radiation $(\lambda=$ $1.54056 \AA$ ). The diffractograms were obtained in $10^{\circ}$ to $90^{\circ}$ range. The crystallite diameter was estimated by Scherrer's equation:

$$
d=\frac{0.9 \lambda}{B \cos \theta}
$$

in which $\lambda$ represents wavelength, $B$ represents full width at half maximum (FWHM) of (104) peak, and $\cos \theta$ represents Bragg angle. The Rietveld refinement has been made, by using the FullProf Suite software, in order to analyze the Xray spectra, in which the following parameters were refined:

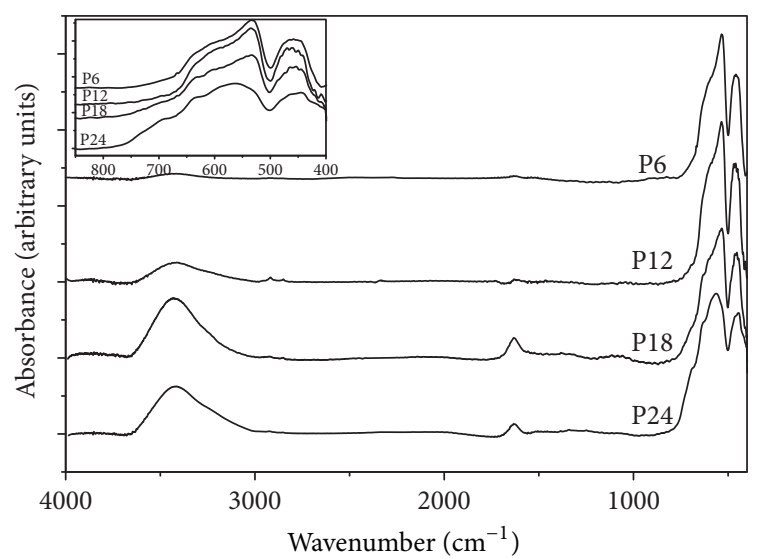

FIGURE 1: FTIR spectra for obtained iron oxides showing the main differences in samples composition with the variation of $\mathrm{Fe}^{3+}$ : PVP monomer ratio.

zero point, scale factor, background, unit cell, half-width, pseudo-Voigt, and asymmetry for the peak shape and thermal isotropic and position factors [23].

Structures of obtained iron oxides were evaluated using a $120 \mathrm{kV}$ JEOL JEM-1400 transmission electron microscopy (TEM), in which samples were put on a thin carbon film $\mathrm{Cu}$ grid (200 mesh) (CF200-Cu, EMS).

The photoacoustic spectra were performed with a monochromatic light emitted by a $1000 \mathrm{~W}$ xenon arc lamp, Oriel Corporation 68820, with a monochromator (model 77250, Oriel Instruments, mechanical chopper, Stanford Research Systems SR40).

The low temperature $(5-300 \mathrm{~K})$ magnetic measurements were performed in a Quantum Design MPMS XL7 SQUID, whereas the room temperature measurements were performed in a Lakeshore vibrating sample magnetometer (VSM-2T) equipped with an argon flow furnace (300-1200 K).

Mössbauer analysis was obtained using spectrometer with constant acceleration, $57 \mathrm{Co}(\mathrm{Rh})$ source of $25 \mathrm{mCi}$ of nominal starting activity. Mössbauer measurements at low temperature were realized using a helium/nitrogen flow cryostat. Spectra were evaluated by nonlinear least-square method using Lorentzian line shapes. Hyperfine magnetic field distribution $\left(B_{\mathrm{hf}}\right)$ was applied as histograms in spectral evaluation. The isomer shift $(\delta)$ data are related to $\alpha$-Fe.

\section{Results and Discussion}

Figure 1 shows the FTIR spectra of obtained iron oxides. These spectra show resembling appearance indicating that the chemical composition of P6, P12, P18, and P24 is similar. The IR bands at $3400 \mathrm{~cm}^{-1}$ and $1600 \mathrm{~cm}^{-1}$ can be assigned to $\mathrm{OH}$-stretching $(\nu \mathrm{OH})$ and $\mathrm{HOH}$-bending $(\delta \mathrm{OH})$ vibrational bands due to the adsorbed water in the sample [24, 25]. The quantity of adsorbed water increases from P6 to P24, along with the increase of the amount of PVP, probably due to the higher amount of carbon present in the samples after the calcination. Carbonaceous residual tends to be good 


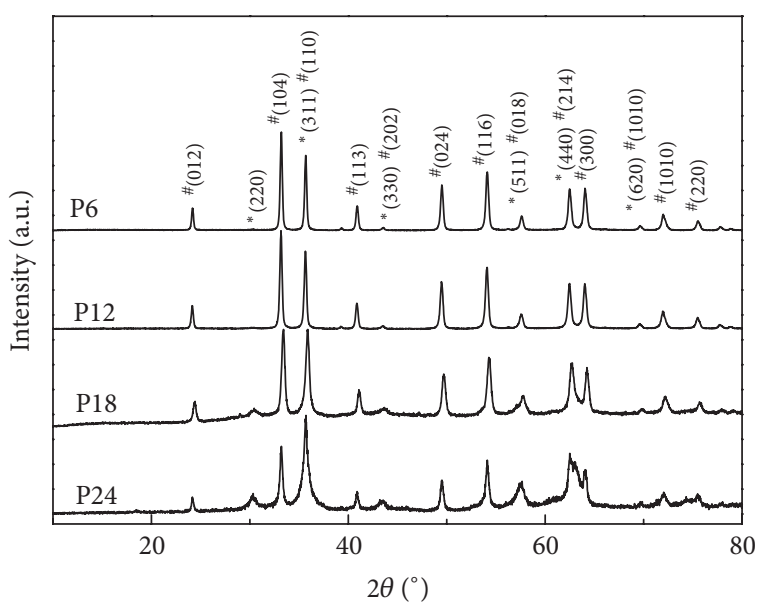

Figure 2: XRD pattern of P6, P12, P18, and P24 samples. The Miller indices of reflection are assigned as * for maghemite and \# for hematite. The prevalence of hematite phase was observed for all samples.

TABLE 1: Hematite and maghemite amount (in weight\%) and hematite nanoparticle average size for the obtained samples by modified sol-gel method using PVP.

\begin{tabular}{lccc}
\hline Sample & $\alpha-\mathrm{Fe}_{2} \mathrm{O}_{3}$ (wt\%) & $\gamma-\mathrm{Fe}_{2} \mathrm{O}_{3}$ (wt\%) & $\begin{array}{c}\text { Hematite nanoparticles } \\
\text { average size (nm) }\end{array}$ \\
\hline P6 & 95 & 5 & 43 \\
P12 & 98 & 2 & 40 \\
P18 & 88 & 12 & 31 \\
P24 & 72 & 28 & 29 \\
\hline
\end{tabular}

adsorbent materials, presenting high amount of adsorbed humidity. The bands in the range of $750-400 \mathrm{~cm}^{-1}$ are related to $\mathrm{Fe}-\mathrm{O}$ lattice vibration. Hematite phase presents bands at 620,540 , and $470 \mathrm{~cm}^{-1}$ and maghemite phase presents bands at $700,660-630,590$, and $430 \mathrm{~cm}^{-1}$, but the positions of the bands are sensitive to the particles size and shape [26, 27].

It can be observed that the shape of the bands at $540 \mathrm{~cm}^{-1}$ (related to hematite phase) presents some differences with P24. This behavior can be attributed to the different phase composition of this sample, indicating higher maghemite contents than the other samples.

The structure, as well as the average nanoparticle size, was analyzed in all samples using X-ray diffraction (Figure 2). The $\mathrm{Fe}_{2} \mathrm{O}_{3}$ phases were estimated using quantitative Rietveld analysis based on the structure data presented in previous studies $[28,29]$. The diffraction patterns are in perfect agreement with the standard JCPDS 33-0664 (hematite), with a minority phase of maghemite JCPDS 39-1346. Crystallite diameters and composition analysis (obtained by XRD) are presented in Table 1.

It is observed that by changing the molar ratio of the $\mathrm{Fe}^{3+}$ : PVP monomer from $1: 6$ to $1: 24$, a decrease in the peaks intensity of hematite phase (104) and an increase in the peaks corresponding to the maghemite phase (311)

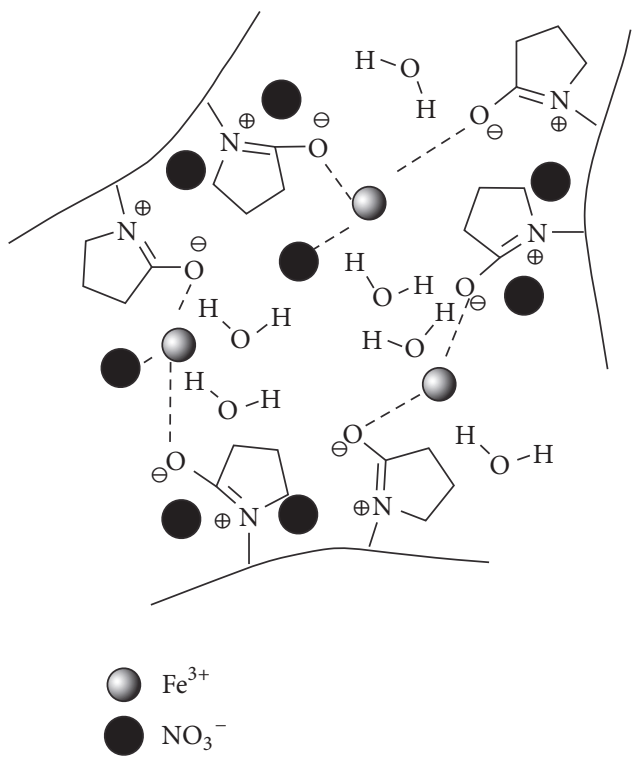

FIGURE 3: Proposed mechanism of interactions between PVP and $\mathrm{Fe}^{3+}$ ions in the formation of iron oxide nanoparticles, adapted from Naseri et al. [35].

are found; however, for all samples, the majority phase observed is hematite. Previous study using PVA on iron oxide nanoparticles synthesis presents distinct behavior, in which the majority phase observed was maghemite [21]. These different behaviors can be attributed to the distinct molecular structure of used polymers (PVP and PVA), since PVA monomers present relative simple chemical structure, with a pendant hydroxyl group, whereas PVP presents a pyrrolidine ring attached to the carbon skeleton. The pyrrolidine ring contains carbonyl groups and a nitrogen heteroatom, beyond the large size of this ligand, compared to hydroxyl group of PVA [30]. Probably, these structural and chemical differences between PVP and PVA influence the different obtained iron oxide majority phases, causing growth of iron oxide crystals in different preferential planes [31, 32]. Also, it is known that high temperatures lead to the transformation of maghemite to hematite [26]. As PVP enthalpy of combustion $\left(133.01 \mathrm{~kJ} \mathrm{~mol}^{-1}\right)$ is more than 10 times higher than PVA enthalpy of combustion $\left(10.95 \mathrm{~kJ} \mathrm{~mol}^{-1}\right)$ [33] it can be assumed that the largest energy release in combustion of PVP causes this transformation, tending to form higher hematite phase amount. Although the maghemite peaks are not visible in the P6 and P12 sample diffractograms, the Rietveld analysis confirms the existence of a small fraction of this phase. The nanoparticles average size shows a decrease as the amount of PVP polymer in relation to iron ions is increased (data showed in Table 1), corroborating the results obtained with PVA polymer [21].

The role of PVP in the reactive liquid medium is to afford a polymeric network to prevent the cation mobility permitting local stoichiometry and preventing precipitation of undesirable crystalline forms. Interactions between PVP cap molecules and iron cations are shown in the scheme presented in Figure 3. Fe (III) cations are linked by the 
strong ionic linkages formed by Fe (III) ions and PVP amide group.

The polymer performs like a support for iron nitrate by means of steric/electrostatic stabilization with pyrrolidine rings (amide functions) and methyl groups. The PVP can be broken into small molecules, producing shorter polymer groups coating the $\mathrm{Fe}$ (III) cations, when those are linked. The Fe (III) ions are regularly distributed inside the networks created by the polymeric chains. The performance ends by loss of water. PVP role is not limited to liquid medium. The polymer may too influence the formation of the nanoparticles nuclei in the thermal degradation.

In agreement with results obtained in previous studies using PVP as a capping agent, but using a different thermal treatment for the synthesis of metal oxides, it can be observed that the PVP amount directly influences the obtained particle size and crystalline phases $[20,34,35]$. During the decomposition of this metal ion with PVP capping, initial iron oxides forms are synthetized inside porous carbonaceous matrix. Then, these initial oxides produce the requested phase of nanostructured $\mathrm{Fe}_{2} \mathrm{O}_{3}$. Carbonaceous material degradation eliminates gases (such as $\mathrm{CO}, \mathrm{CO}_{2}, \mathrm{NO}_{X}$, and water vapor) that maintain the combustion energy loss and prevent the aggregation of small particles during the nanoparticles synthesis process $[36,37]$.

In order to evaluate the diameter and morphology of the obtained nanoparticles, the samples were observed using transmission electron microscopy (TEM).

TEM micrographs of P6, P12, P18, and P24 samples are shown in Figure 4. The obtained nanoparticles present sizes that range from 25 to $45 \mathrm{~nm}$ (corroborating with average size of $42 \mathrm{~nm}$ estimated by XRD analysis). These particles present a hexagonal tendency with clear facets. Figure 4(e) shows TEM micrograph of a unique iron oxide crystallite (sample P24), clearly indicating the hexagonal morphology of hematite nanoparticles, the majority phase obtained. The observed morphology is common for this crystalline phase of iron oxide [38, 39].

Hematite and maghemite are n-type semiconductors, and intending to study the optical properties (such as absorption and optical band gap energy) of the obtained samples, the photoacoustic UV-Vis spectrum for P12 sample (Figure 5) was measured. Photoacoustic is a photothermal phenomenon used to evaluate the thermooptical characteristics of materials, enlightening a sample with a modulated light beam and measuring the sound effect induced in consequence of temperature change in a solid. The main advantage of this method is that it allows the study of weakly absorbing or opaque samples, which cannot be evaluated by UV-Vis spectroscopy standard method [40, 41].

A broad absorption was registered near the $280-550 \mathrm{~nm}$ range of the spectrum. It is the consequence of different electronic transitions: $\mathrm{Fe}(\mathrm{III})$ crystal transitions, magnetically coupled $\mathrm{Fe}(\mathrm{III})$ interactions, and oxygen-iron charge transfer excitations from $\mathrm{O}(2 \mathrm{p})$ nonbonding valence bands to the $\mathrm{Fe}(3 \mathrm{~d})$ ligand field orbitals. The charge transfer transitions involving $\mathrm{Fe}^{\mathrm{III}}-\mathrm{O}$ are mainly responsible for absorption of visible light. The electronic transitions ${ }^{4} \mathrm{~A}_{1} 20 \leftarrow{ }^{6} \mathrm{~A}$, dd electron pair transition, and ${ }^{4} \mathrm{~T}_{2} \leftarrow{ }^{6} \mathrm{~A}_{1}$ present the respective band position range in $420-440 \mathrm{~nm}, 520-570 \mathrm{~nm}$, and $670-700 \mathrm{~nm}$ for hematite and $420-430 \mathrm{~nm}, 490-500 \mathrm{~nm}$, and $650-700 \mathrm{~nm}$ for maghemite [26].

Based on the photoacoustic spectrum data, the band gap energies were calculated, using Tauc's equation [42]:

$$
(\alpha h v)=A\left(h \nu-E_{g}\right)^{m},
$$

in which $\alpha$ is the absorption coefficient, $A$ is a constant related to the effective mass of the electrons and holes, $m$ is 0.5 for allowed direct transition and 2 for allowed indirect transitions, and $E_{g}$ is the energy gap. The band gap values were determined from the curve extrapolation, exhibiting an indirect transition at nearly $1.44 \mathrm{eV}$ and direct transition at $1.73 \mathrm{eV}$. Higher values of direct band gap $(2.1 \mathrm{eV})$ have already been reported previously for bulk or nanoparticle of hematite/maghemite $[43,44]$. It is possible that the energy gap is influenced by the obtained iron oxide nanoparticles size as well as the presence of two different crystalline phases [45]. The indirect transition has been identified as a spinforbidden $\mathrm{Fe}^{3+} 3 \mathrm{~d} \rightarrow 3 \mathrm{~d}$ excitation while the direct transition corresponds to the $\mathrm{O}^{2-} 2 \mathrm{p} \rightarrow \mathrm{Fe}^{3+} 3 \mathrm{~d}$ charge transfer $[46,47]$.

The magnetization curves for all samples (Figure 6) were measured as a function of temperature $(5-300 \mathrm{~K})$, for an applied magnetic field of $0.05 \mathrm{~T}$, using zero-field-cooling (ZFC) and field-cooled-warming (FCW) procedures.

In the ZFC measurements, the samples were cooled down, from $300 \mathrm{~K}$ to $5 \mathrm{~K}$, without the presence of an applied magnetic field. After reach $5 \mathrm{~K}$, the magnetic field was applied and the magnetization was measured during the temperature run. In the FCW measurements, the samples were cooled down to $5 \mathrm{~K}$ with the same magnetic field applied during the ZFC. After reaching $5 \mathrm{~K}$, the magnetization was acquired during the temperature run.

All the ZFC-FCW curves (Figure 6) show irreversibility below $T_{\text {irr }}$ (temperature below which the ZFC and FCW curves are separated) and these temperatures were found to be very close to room temperature $(\sim 297 \mathrm{~K})$ for the all samples. There are broad peaks below $273 \mathrm{~K}$ in the ZFC curves for P18 and P24 samples, with a maximum at $T_{\text {peak }} \sim$ $233 \mathrm{~K}$ and $246 \mathrm{~K}$, respectively, that is characteristic of the unblocking step of superparamagnetic nanoparticles [21, 4850].

However, for P6 and P12 samples, that present almost the total composition formed by hematite phase, a transition can be observed in both ZFC and FCW curves, due to Morin transition. The magnetic moments of hematite are nearly perpendicular to the rhombohedral axis with a slight inclining of the magnetic sublattices, resulting in a small net magnetic moment. Throughout freezing, particles suffer a first-order spin reorientation transition. The moments are oriented antiferromagnetically with the rhombohedral axis, and the net magnetic moment reaches zero. For oxides in massive state, Morin transition temperature, $T_{m}$, is nearly $260 \mathrm{~K}$, but, in nanostructured materials, $T_{m}$ varies according to crystallite diameter [51, 52]. For P6 and P12, with 40 and 


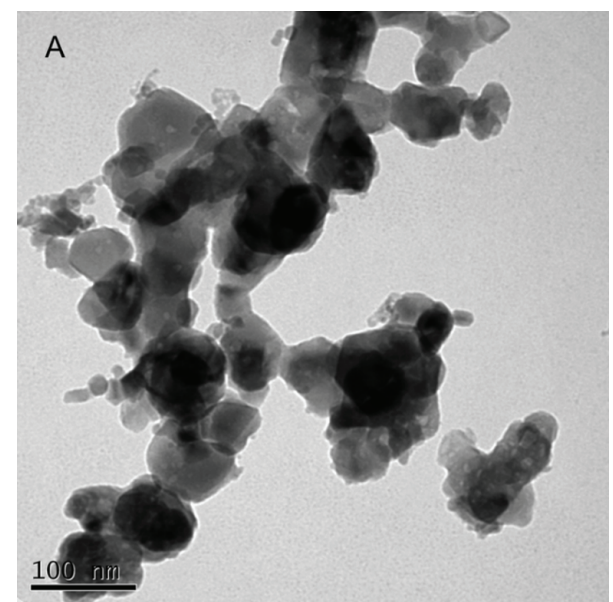

(a)

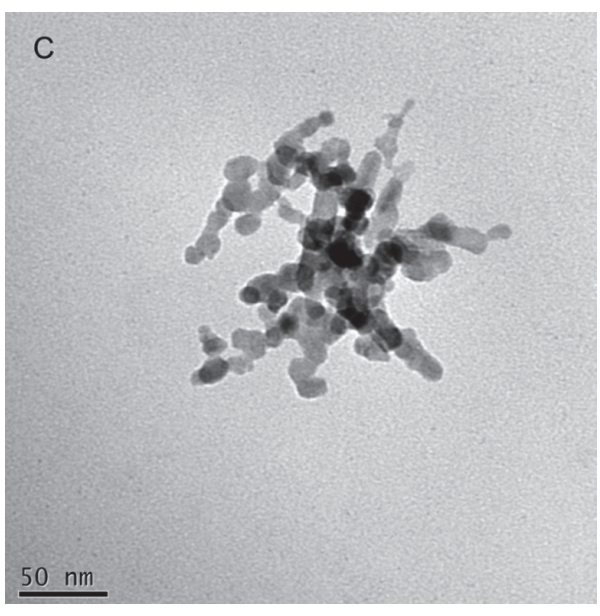

(c)

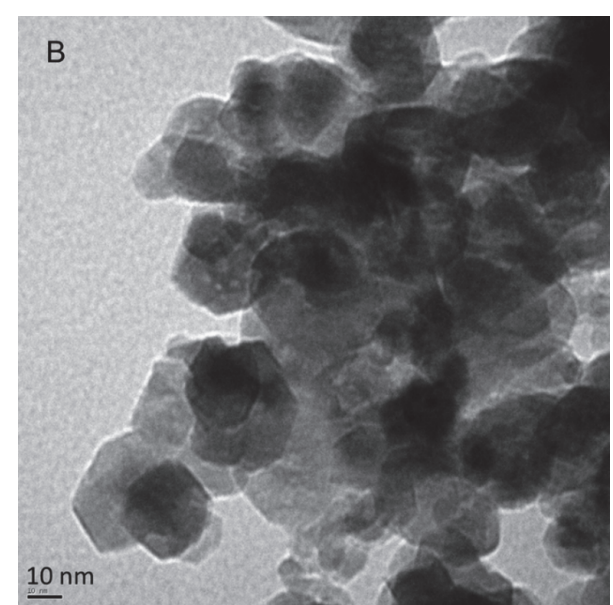

(b)

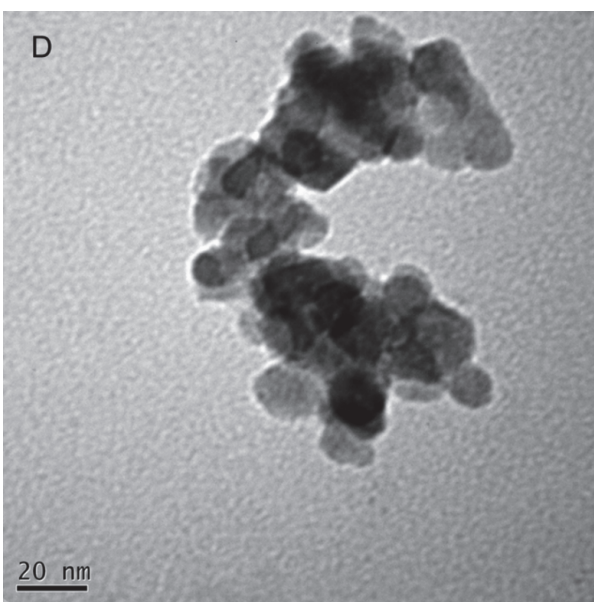

(d)

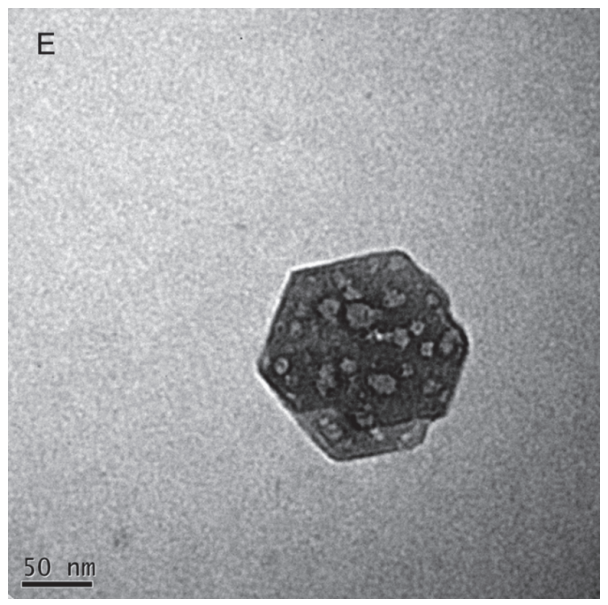

(e)

Figure 4: TEM micrograph of the P6 (a), P12 (b), P18 (c), and P24 (d) samples and a unique crystallite of P24 (e) with hexagonal projections, indicating well developed facets (JEOL JEM-1400 at $120 \mathrm{kV}$ ). 


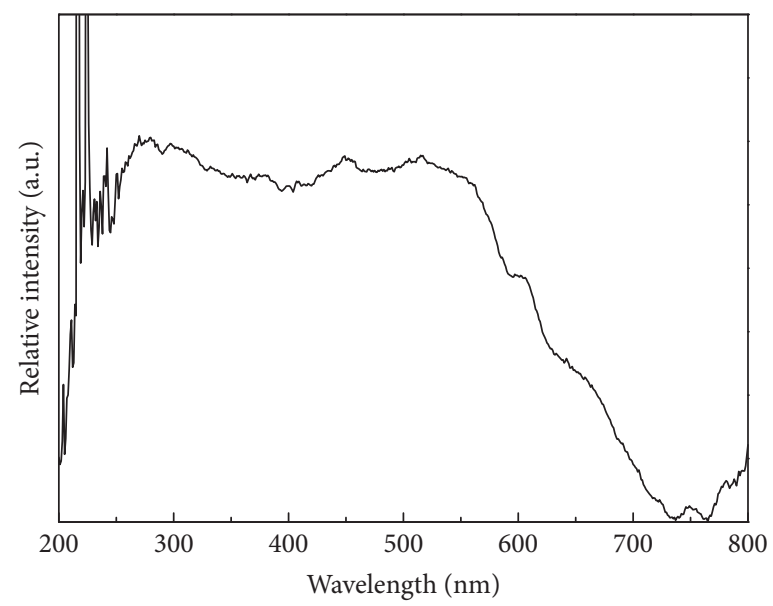

Figure 5: Photoacoustic UV-Vis spectrum of P12 sample showing a broad absorption in the range of 280-550 nm due to the sample electronic transitions.
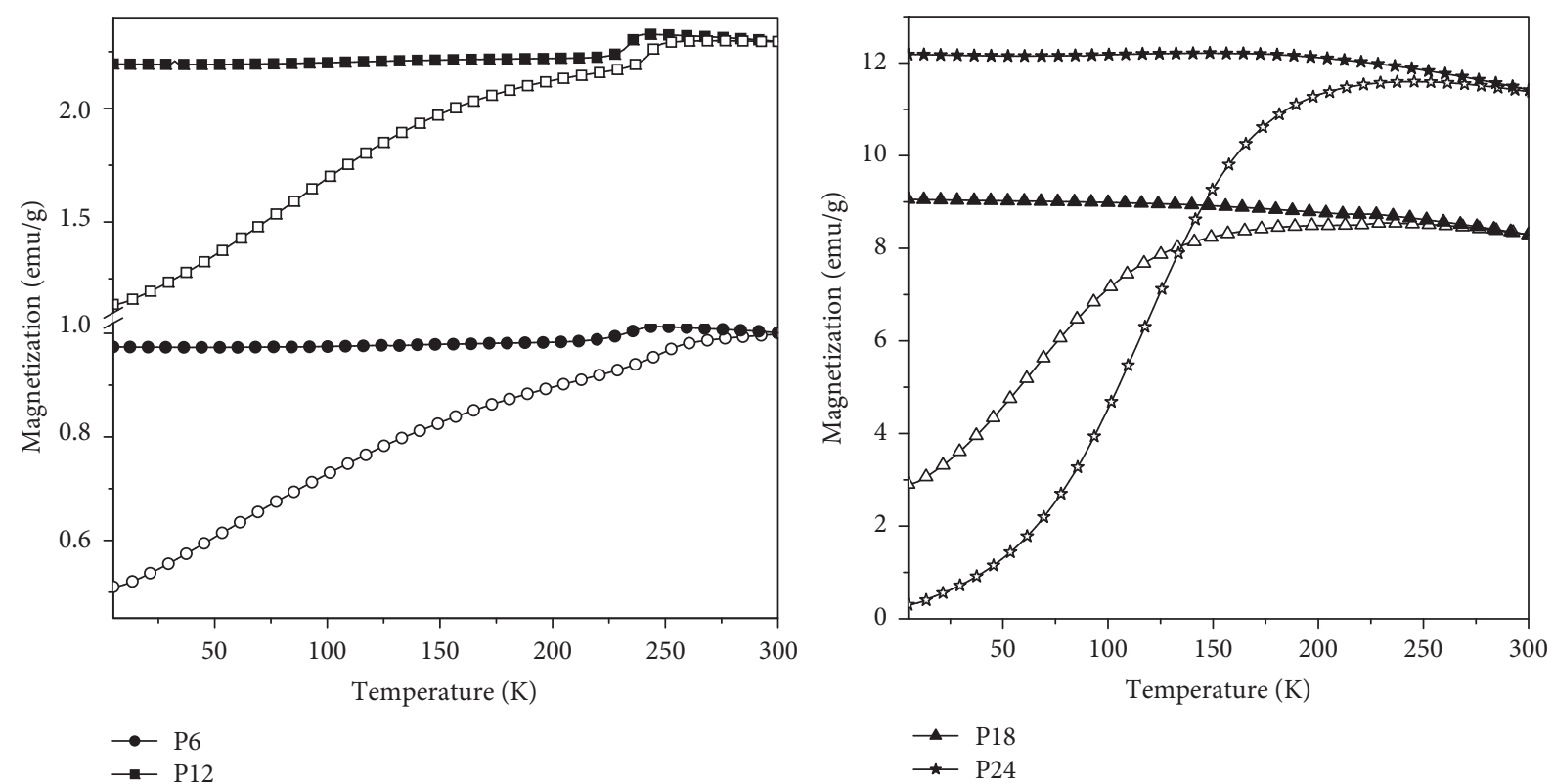

FIGURE 6: ZFC (open symbols) and FC (solid symbols) magnetization curves of P6, P12, P18, and P24 samples at $H=500$ Oe.

$43 \mathrm{~nm}$, respectively, $T_{m}$ are nearly $232 \mathrm{~K}$ for FCW curves and $242 \mathrm{~K}$ for ZFC curves for both samples.

The magnetization versus magnetic field curves, performed at room temperature, is shown in Figure 7.

The maximum applied field of $2 \mathrm{~T}$ was sufficient to saturate all the samples. As can be seen in Figure 7, the highest magnetization saturation $(33.3 \mathrm{emu} / \mathrm{g})$ was achieved by the sample P24 (72 wt \% hematite and $28 \mathrm{wt} \%$ maghemite), followed by $12.4 \mathrm{emu} / \mathrm{g}$ of the sample P18 ( $88 \mathrm{wt} \%$ hematite and $12 \mathrm{wt} \%$ maghemite) and $9.8 \mathrm{emu} / \mathrm{g}$ and $2.2 \mathrm{emu} / \mathrm{g}$, respectively, by the samples P12 and P6. Although sample P6 presents more maghemite amount (5\%) then sample P12 (2\%), the latter presents smaller particles, and possibly, due to this, a higher magnetization saturation than the first.
This can be explained by the presence of defects in the hematite nanoparticles caused by oxygen vacancies near the surface [53]. These defects could destroy the antiferromagnetic superexchange interaction of the $\mathrm{Fe}^{3+}-\mathrm{O}^{2-}-\mathrm{Fe}^{3+}$ leading to a ferromagnetic ordering [54].

Figure 8 shows the room temperature transmission of Mössbauer spectra of the samples P6, P12, P18, and P24. Table 2 gives the results of the spectra fitting.

At room temperature, hematite spectrum consists of a sextet with a $\Delta E$ of $-0.20 \mathrm{~mm} \mathrm{~s}^{-1}$, a $B_{\mathrm{hf}}$ of $51.8 \mathrm{~T}$, and $\delta$ of $0.38 \mathrm{~mm} \mathrm{~s}^{-1}[26,55]$. Only one crystalline structure site is present for $\mathrm{Fe}$ (III) in hexagonal hematite [56]. Maghemite presents a spinel lattice, in which Fe(III) sites can be represented by $\mathrm{Fe}(\mathrm{III})|\square \mathrm{Fe}(\mathrm{III})| \mathrm{O}_{3}$, tetrahedral sites are 


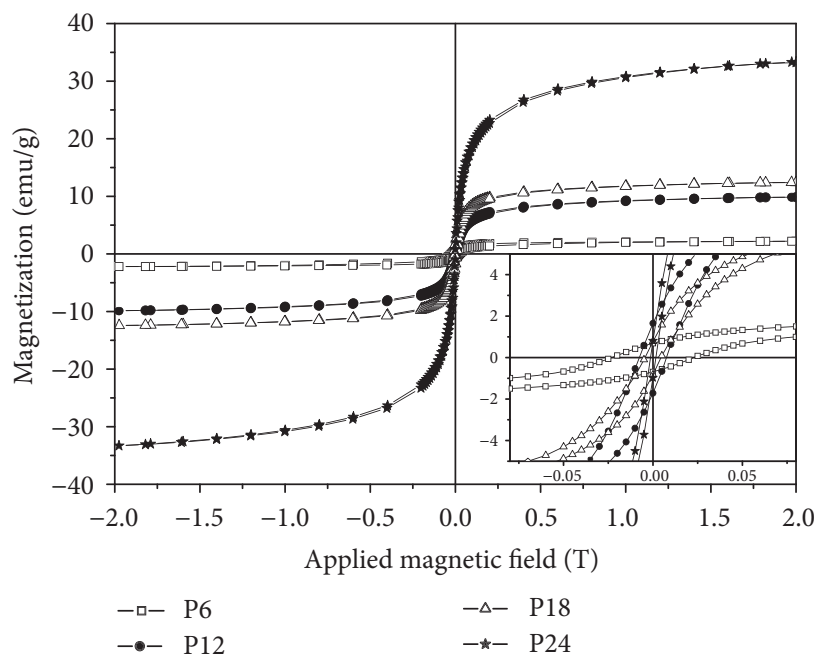

FIGURE 7: Room temperature magnetization versus magnetic applied field curves showing the dependence of magnetization saturation with $\mathrm{Fe}^{3+}$ : PVP monomer ratio.

TABLE 2: Hyperfine parameters and subspectral areas for the obtained iron oxides.

\begin{tabular}{|c|c|c|c|c|c|c|}
\hline Sample & Subespect. & $\begin{array}{c}\Gamma \\
(\mathrm{mm} / \mathrm{s})\end{array}$ & $\begin{array}{c}\delta \\
(\mathrm{mm} / \mathrm{s})\end{array}$ & $\begin{array}{c}\Delta E \\
(\mathrm{~mm} / \mathrm{s})\end{array}$ & $B_{\mathrm{hf}}(\mathrm{T})$ & $A(\%)$ \\
\hline P6 & Sext. H & 0.39 & 0.37 & -0.20 & 51.1 & 100 \\
\hline $\mathrm{P} 12$ & Sext. H & 0.38 & 0.37 & -0.21 & 51.2 & 100 \\
\hline \multirow{2}{*}{ P18 } & Distrib. M & 0.30 & 0.31 & 0.00 & 42.4 & 20.2 \\
\hline & Sext. H & 0.46 & 0.36 & -0.20 & 50.4 & 79.8 \\
\hline \multirow{2}{*}{$\mathrm{P} 24$} & Distrib. M & 0.30 & 0.31 & 0.01 & 47.0 & 21.1 \\
\hline & Sext. H & 0.44 & 0.41 & -0.20 & 51.1 & 78.9 \\
\hline
\end{tabular}

$\Gamma$ : linewidth; $\delta$ : isomer shift; $\Delta E$ : quadrupole splitting; $B_{\mathrm{hf}}$ : hyperfine magnetic field; $A$ : area.

represented by $\mathrm{Fe}(\mathrm{III})$, and octahedral sites by $|\mathrm{Fe}(\mathrm{III})|$ in a cubic spinel structure. The symbol $\square$ represents vacancies in maghemite. The spectrum of maghemite is composed of two sextets, hardly distinguishable at room temperature, due to the fact that hyperfine parameters for the two sites are very similar in magnitude. Commonly occurring effects such as small particle size distributions tend to cause line broadening and/or a line-shape asymmetry, and, in many cases, the room temperature spectrum has to be fitted with a distribution of unresolved A- and B-site hyperfine fields [57]. This is the case here, where the maghemite phase was fitted as distribution M. In surveying the literature for maghemite, it was noticed that an inconceivably wide scatter for the $\delta$ exists, with the values at room temperature ranging from $0.04 \mathrm{~mm} \mathrm{~s}^{-1}$ up to $0.30 \mathrm{~mm} \mathrm{~s}^{-1}$ for A-site and from $0.04 \mathrm{~mm} \mathrm{~s}^{-1}$ up to $0.40 \mathrm{~mm} \mathrm{~s}^{-1}$ for B-site and $B_{\mathrm{hf}}$ values for the two sites were $50.0 \mathrm{~T}[26,57]$. The spectra for all samples were adjusted by introducing one sextet relative to hematite and, for P18 and P24, also a distribution relative to maghemite. It can be observed that the Mössbauer spectra of hematite and maghemite overlap at room temperature, so it is difficult to quantify the relative proportions of these phases in the samples. Due to this, there may be slight difference between the proportions of crystalline phases ( $\alpha$ $\mathrm{Fe}_{2} \mathrm{O}_{3}$ and $\gamma$ - $\mathrm{Fe}_{2} \mathrm{O}_{3}$ ) determined by Mössbauer spectroscopy and Rietveld refinement.

\section{Conclusions}

This work performed a research in order to comprehend how PVP affects the synthesis of nanostructured iron oxide by a modified sol-gel method. Succinctly, according to the data obtained by XRD diffractograms, TEM micrographs, FTIR spectra, UV-Vis photoacoustic spectra, Mössbauer spectra, SQUID, and VSM curves, PVP act to control the growth and crystalline phase formation of maghemite and hematite. Since the PVP content is increased, the samples do not show Morin transition present in the samples with lower PVP content and the saturation magnetization increases as the PVP amount increases. It is impossible to define an optimum $\mathrm{Fe}^{3+}$ : PVP monomer ratio because it depends on the sample application and whether it is more important to achieve a higher magnetization or use the Morin transition. Then, this study shows that it is possible to obtain samples with different behaviors only by changing the PVP content. 


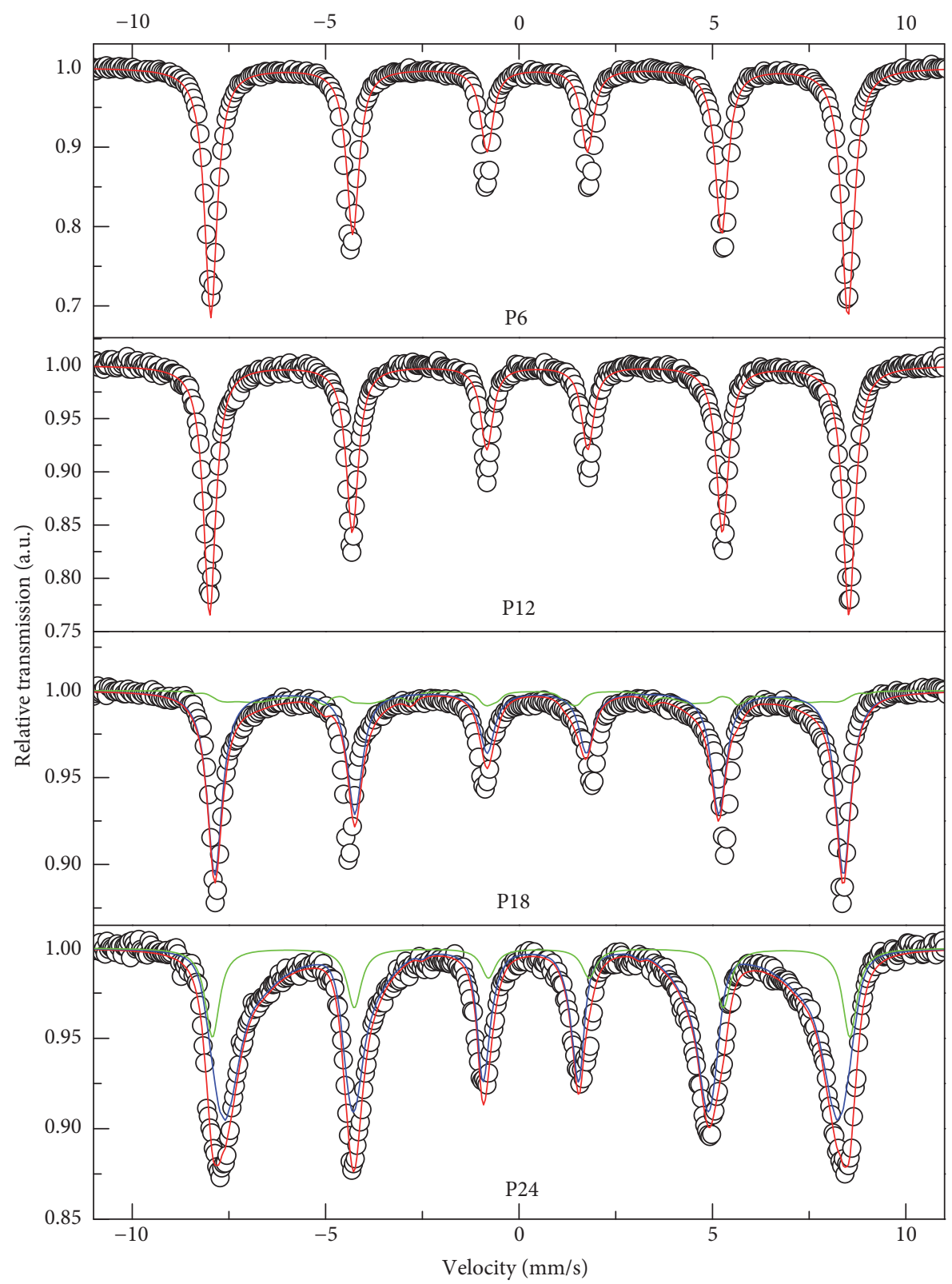

FIgURE 8: Mössbauer spectra for P6, P12, P18, and P24 samples taken at room temperature.

\section{Conflicts of Interest}

The authors declare that there are no conflicts of interest regarding the publication of this paper.

\section{Acknowledgments}

The authors would like to thank Professor Dr. Mauro Baesso and Ms. Gutierrez Rodriguês de Morais for UVVis photoacoustic measurements and Professor Dr. Eduardo Radovanovic for TEM micrographs. The authors also thank the financial support of Capes, DGU 184-09, and MCI Spain, PHB 2008-0044-PC.

\section{References}

[1] P. Xu, G. M. Zeng, D. L. Huang et al., "Use of iron oxide nanomaterials in wastewater treatment: a review," Science of the Total Environment, vol. 424, pp. 1-10, 2012.

[2] F. Rajabi, N. Karimi, M. R. Saidi, A. Primo, R. S. Varma, and R. Luque, "Unprecedented selective oxidation of styrene derivatives using a supported iron oxide nanocatalyst in aqueous medium," Advanced Synthesis and Catalysis, pp. 1707-1711, 2012.

[3] H. Kitamura, L. Zhao, B. T. Hang, S. Okada, and J.-I. Yamaki, "Effect of binder materials on cycling performance of $\mathrm{Fe}_{2} \mathrm{O}_{3}$ electrodes in alkaline solution," Journal of Power Sources, vol. 208, pp. 391-396, 2012.

[4] M. F. Silva, A. A. Winkler Hechenleitner, D. M. F. de Oliveira et al., "Optimization of maghemite-loaded PLGA nanospheres for 
biomedical applications," European Journal of Pharmaceutical Sciences, vol. 49, pp. 343-351, 2013.

[5] A. Figuerola, R. Di Corato, L. Manna, and T. Pellegrino, "From iron oxide nanoparticles towards advanced iron-based inorganic materials designed for biomedical applications," Pharmacological Research, pp. 126-143, 2010.

[6] H.-M. Yang, B. C. Oh, J. H. Kim et al., "Multifunctional poly(aspartic acid) nanoparticles containing iron oxide nanocrystals and doxorubicin for simultaneous cancer diagnosis and therapy," Colloids and Surfaces A: Physicochemical and Engineering Aspects, vol. 391, no. 1-3, pp. 208-215, 2011.

[7] M. Mahmoudi, S. Sant, B. Wang, S. Laurent, and T. Sen, "Superparamagnetic iron oxide nanoparticles (SPIONs): development, surface modification and applications in chemotherapy," Advanced Drug Delivery Reviews, pp. 24-46, 2011.

[8] Y. Wu and X. Wang, "Preparation and characterization of singlephase $\alpha-\mathrm{Fe}_{2} \mathrm{O}_{3}$ nano-powders by Pechini sol-gel method," Materials Letters, vol. 65, no. 13, pp. 2062-2065, 2011.

[9] D. M. Fernandes, A. A. Winkler Hechenleitner, M. F. Silva et al., "Preparation and characterization of $\mathrm{NiO}, \mathrm{Fe}_{2} \mathrm{O}_{3}, \mathrm{Ni}_{0.04} \mathrm{Zn}_{0.96} \mathrm{O}$ and $\mathrm{Fe}_{0.03} \mathrm{Zn}_{0.97} \mathrm{O}$ Nanoparticles," Materials Chemistry and Physics, pp. 447-452, 2009.

[10] A. Hassanjani-Roshan, M. R. Vaezi, A. Shokuhfar, and Z. Rajabali, "Synthesis of iron oxide nanoparticles via sonochemical method and their characterization," Particuology, vol. 9, no. 1, pp. 95-99, 2011.

[11] L. Chen, Z. Lin, C. Zhao, Y. Zheng, Y. Zhou, and H. Peng, "Direct synthesis and characterization of mesoporous $\mathrm{Fe}_{3} \mathrm{O}_{4}$ through pyrolysis of ferric nitrate-ethylene glycol gel," Journal of Alloys and Compounds, vol. 509, pp. L1-L5, 2011.

[12] S. Yang, Y.-H. Jang, C. H. Kim et al., "A flame metal combustion method for production of nanoparticles," Powder Technology, vol. 197, no. 3, pp. 170-176, 2010.

[13] L.-H. Han, H. Liu, and Y. Wei, "In situ synthesis of hematite nanoparticles using a low-temperature microemulsion method," Powder Technology, vol. 207, no. 1-3, pp. 42-46, 2011.

[14] J.-P. Jolivet, S. Cassaignon, C. Chanéac, D. Chiche, O. Durupthy, and D. Portehault, "Design of metal oxide nanoparticles: control of size, shape, crystalline structure and functionalization by aqueous chemistry," Comptes Rendus Chimie, vol. 13, no. 1-2, pp. 40-51, 2010.

[15] A. Khaleel and A. Al-Marzouqi, "Alkoxide-free sol-gel synthesis of aerogel iron-chromium mixed oxides with unique textural properties," Materials Letters, vol. 68, pp. 385-387, 2012.

[16] S. Komarneni, W. Hu, Y. D. Noh et al., "Magnetite syntheses from room temperature to $150^{\circ} \mathrm{C}$ with and without microwaves," Ceramics International, vol. 38, no. 3, pp. 2563-2568, 2012.

[17] D. M. Fernandes, A. A. W. Hechenleitner, M. F. Silva et al., "Preparation and characterization of $\mathrm{NiO}, \mathrm{Fe}_{2} \mathrm{O}_{3}, \mathrm{Ni}_{0.04} \mathrm{Zn}_{0.96} \mathrm{O}$ and $\mathrm{Fe}_{0.03} \mathrm{Zn}_{0.97} \mathrm{O}$ nanoparticles," Materials Chemistry and Physics, vol. 118, no. 2-3, pp. 447-452, 2009.

[18] D. M. Fernandes, R. Silva, A. A. W. Hechenleitner, E. Radovanovic, M. A. C. Melo, and E. A. G. Pineda, "Synthesis and characterization of $\mathrm{ZnO}, \mathrm{CuO}$ and a mixed $\mathrm{Zn}$ and $\mathrm{Cu}$ oxide," Materials Chemistry and Physics, vol. 115, no. 1, pp. 110-115, 2009.

[19] D. M. Fernandes, J. L. Andrade, M. K. Lima et al., "Thermal and photochemical effects on the structure, morphology, thermal and optical properties of PVA/ $\mathrm{Ni}_{0.04} \mathrm{Zn}_{0.96} \mathrm{O}$ and PVA $/ \mathrm{Fe}_{0.03} \mathrm{Zn}_{0.97} \mathrm{O}$ nanocomposite films," Polymer Degradation and Stability, vol. 98, no. 9, pp. 1862-1868, 2013.
[20] M. G. Naseri, E. Saion, and N. K. Zadeh, "The amazing effects and role of PVP on the crystallinity, phase composition and morphology of nickel ferrite nanoparticles prepared by thermal treatment method," International Nano Letters, vol. 3, pp. 1-8, 2013.

[21] M. F. Silva, L. A. S. De Oliveira, M. A. Ciciliati et al., "Nanometric particle size and phase controlled synthesis and characterization of $\gamma-\mathrm{Fe}_{2} \mathrm{O}_{3}$ or $(\alpha+\gamma)-\mathrm{Fe}_{2} \mathrm{O}_{3}$ by a modified solgel method," Journal of Applied Physics, vol. 114, no. 10, Article ID 104311, 2013.

[22] M. K. Lima, D. M. Fernandes, M. F. Silva et al., "Co-doped ZnO nanoparticles synthesized by an adapted sol-gel method: effects on the structural, optical, photocatalytic and antibacterial properties," Journal of Sol-Gel Science and Technology, vol. 72, no. 2, pp. 301-309, 2014.

[23] J. Rodríguez-Carvajal, "Recent advances in magnetic structure determination by neutron powder diffraction," Physica B: Physics of Condensed Matter, vol. 192, no. 1-2, pp. 55-69, 1993.

[24] M. Gotić and S. Musić, "Mössbauer, FT-IR and FE SEM investigation of iron oxides precipitated from $\mathrm{FeSO}_{4}$ solutions," Journal of Molecular Structure, vol. 834-836, pp. 445-453, 2007.

[25] D. Predoi, "A study on iron oxide nanoparticles coated with dextrin obtained by coprecipitation," Digest Journal of Nanomaterials and Biostructures, vol. 2, no. 1, pp. 169-173, 2007.

[26] R. M. Cornell and U. Sshwertmann, The Iron Oxides: Structures, Properties, Reactions, Occurrences and Uses, Wiley-VCH, Weinheim, Germany, 2003.

[27] H. Namduri and S. Nasrazadani, "Quantitative analysis of iron oxides using Fourier transform infrared spectrophotometry," Corrosion Science, vol. 50, no. 9, pp. 2493-2497, 2008.

[28] W. Wu, X. H. Xiao, S. F. Zhang et al., "Synthesis and magnetic properties of maghemite $\left(\gamma-\mathrm{Fe}_{2} \mathrm{O}_{3}\right)$ short-nanotubes," Nanoscale Research Letters, vol. 5, no. 9, pp. 1474-1479, 2010.

[29] S. Asuha, S. Zhao, X. H. Jin, M. M. Hai, and H. P. Bao, "Effects of synthetic routes of $\mathrm{Fe}$-urea complex on the synthesis of $\gamma-\mathrm{Fe}_{2} \mathrm{O}_{3}$ nanopowder," Applied Surface Science, vol. 255, no. 21, pp. 88978901, 2009.

[30] A. Goel and N. Rani, "Effect of PVP, PVA and POLE surfactants on the size of iridium nanoparticles," Open Journal of Inorganic Chemistry, vol. 2, pp. 67-73, 2012.

[31] N. Sakulchaicharoen, D. M. O'Carroll, and J. E. Herrera, "Enhanced stability and dechlorination activity of pre-synthesis stabilized nanoscale FePd particles," Journal of Contaminant Hydrology, vol. 118, no. 3-4, pp. 117-127, 2010.

[32] N. Rajeswari, S. Selvasekarapandian, M. Prabu, S. Karthikeyan, and C. Sanjeeviraja, "Lithium ion conducting solid polymer blend electrolyte based on bio-degradable polymers," Bulletin of Materials Science, vol. 36, no. 2, pp. 333-339, 2013.

[33] M. H. Abou-Taleb, "Thermal and spectroscopic studies of poly(n-vinyl pyrrolidone)/poly(vinyl alcohol) blend films," Journal of Applied Polymer Science, vol. 114, no. 2, pp. 1202-1207, 2009.

[34] M. G. Naseri, E. B. Saion, H. A. Ahangar, M. Hashim, and A. H. Shaari, "Simple preparation and characterization of nickel ferrite nanocrystals by a thermal treatment method," Powder Technology, vol. 212, no. 1, pp. 80-88, 2011.

[35] M. G. Naseri, E. B. Saion, M. Hashim, A. H. Shaari, and H. A. Ahangar, "Synthesis and characterization of zinc ferrite nanoparticles by a thermal treatment method," Solid State Communications, vol. 151, no. 14-15, pp. 1031-1035, 2011. 
[36] P. P. Sarangi, B. Naik, and N. N. Ghosh, "Low temperature synthesis of single-phase $\alpha-\mathrm{Fe}_{2} \mathrm{O}_{3}$ nano-powders by using simple but novel chemical methods," Powder Technology, vol. 192, no. 3, pp. 245-249, 2009.

[37] P. P. Sarangi, B. D. Naik, S. R. Vadera, M. K. Patra, C. Prakash, and N. N. Ghosh, "Development of simple chemical method for synthesis of single phase Ni-Zn ferrite nanopowders," Materials Technology, vol. 24, no. 2, pp. 97-99, 2009.

[38] N. K. Chaudhari, H. Chan Kim, D. Son, and J.-S. Yu, "Easy synthesis and characterization of single-crystalline hexagonal prism-shaped hematite $\alpha$ - $\mathrm{Fe}_{2} \mathrm{O}_{3}$ in aqueous media," CrystEngComm, vol. 11, no. 11, pp. 2264-2267, 2009.

[39] S. Okada, K. Takagi, and K. Ozaki, "Synthesis of submicron plate-like hematite without organic additives and reduction to plate-like $\alpha$-Fe," Materials Letters, vol. 140, pp. 135-139, 2015.

[40] A. C. Bento, D. T. Dias, L. Olenka, A. N. Medina, and M. L. Baesso, "On the application of the photoacoustic methods for the determination of thermo-optical properties of polymers," Brazilian Journal of Physics, vol. 32, no. 2, pp. 483-494, 2002.

[41] H. Vargas and L. C. M. Miranda, "Photoacoustic and related photothermal techniques," Physics Reports, vol. 161, no. 2, pp. 43-101, 1988.

[42] J. Tauc, R. Grigorovic, and A. Vancu, "Optical properties and electronic structure of amorphous germanium," Physica Status Solidi B, vol. 15, no. 2, pp. 627-637, 1966.

[43] M. Tadić, N. Čitaković, M. Panjan, Z. Stojanović, D. Marković, and V. Spasojević, "Synthesis, morphology, microstructure and magnetic properties of hematite submicron particles," Journal of Alloys and Compounds, vol. 509, no. 28, pp. 7639-7644, 2011.

[44] J. A. Glasscock, P. R. F. Barnes, I. C. Plumb, A. Bendavid, and P. J. Martin, "Structural, optical and electrical properties of undoped polycrystalline hematite thin films produced using filtered arc deposition," Thin Solid Films, vol. 516, no. 8, pp. 1716-1724, 2008.

[45] T. Echigo, D. M. Aruguete, M. Murayama, and M. F. Hochella, "Influence of size, morphology, surface structure, and aggregation state on reductive dissolution of hematite nanoparticles with ascorbic acid," Geochimica et Cosmochimica Acta, vol. 90, pp. 149-162, 2012.

[46] A. Duret and M. Grätzel, "Visible light-induced water oxidation on mesoscopic $\alpha-\mathrm{Fe}_{2} \mathrm{O}_{3}$ films made by ultrasonic spray pyrolysis," Journal of Physical Chemistry B, vol. 109, no. 36, pp. 1718417191, 2005.

[47] F. L. Souza, K. P. Lopes, P. A. P. Nascente, and E. R. Leite, "Nanostructured hematite thin films produced by spin-coating deposition solution: application in water splitting," Solar Energy Materials \& Solar Cells, vol. 93, no. 3, pp. 362-368, 2009.

[48] H. Nirschl and K. Keller, Upscaling of Bio-Nano-Processes: Selective Bioseparation by Magnetic Particles, Springer, Berlin, Germany, 2014.

[49] A. G. Kolhatkar, A. C. Jamison, D. Litvinov, R. C. Willson, and T. R. Lee, "Tuning the magnetic properties of nanoparticles," International Journal of Molecular Sciences, vol. 14, no. 8, pp. 15977-16009, 2013.

[50] L. A. S. De Oliveira, A. Pentón-Madrigal, A. P. Guimarães, and J. P. Sinnecker, "Thermally activated processes and superparamagnetism in $\mathrm{Bi}_{12} \mathrm{MnO}_{20}$ nanoparticles: a comparative study," Journal of Magnetism and Magnetic Materials, vol. 401, pp. 890896, 2016.

[51] J. I. Pérez-Landazábal, C. Gómez-Polo, V. Recarte et al., "Morin transition in Hematite nanoparticles analyzed by neutron diffraction," Journal of Physics: Conference Series, vol. 663, no. 1, Article ID 012003, 2015.
[52] Ö. Özdemir, D. J. Dunlop, and T. S. Berquó, "Morin transition in hematite: size dependence and thermal hysteresis," Geochemistry, Geophysics, Geosystems, vol. 9, no. 10, Article ID Q10Z01, 2008.

[53] J. Wu, S. Mao, Z.-G. Ye, Z. Xie, and L. Zheng, "Roomtemperature weak ferromagnetism induced by point defects in $\alpha-\mathrm{Fe}_{2} \mathrm{O}_{3}$," ACS Applied Materials and Interfaces, vol. 2, no. 6, pp. 1561-1564, 2010.

[54] N. D. Phu, D. T. Ngo, L. H. Hoang, N. H. Luong, N. Chau, and N. H. Hai, "Crystallization process and magnetic properties of amorphous iron oxide nanoparticles," Journal of Physics D: Applied Physics, vol. 44, no. 34, Article ID 345002, 2011.

[55] A. T. Goulart, M. F. de Jesus Filho, J. D. Fabris, and J. M. D. Coey, "Quantitative Mössbauer analysis of maghemite-hematite mixtures in external applied field," Hyperfine Interactions, vol. 83, no. 1, pp. 451-455, 1994.

[56] Harshada Nagar, N. V. Kulkarni, S. Karmakar et al., "Mössbauer spectroscopic investigations of nanophase iron oxides synthesized by thermal plasma route," Materials Characterization, vol. 59, no. 9, pp. 1215-1220, 2008.

[57] G. M. Da Costa, E. De Grave, L. H. Bowen, R. E. Vandenberghe, and P. M. A. De Bakker, "The center shift in Mossbauer spectra of maghemite and aluminum maghemites," Clays and Clay Minerals, vol. 42, no. 5, pp. 628-633, 1994. 

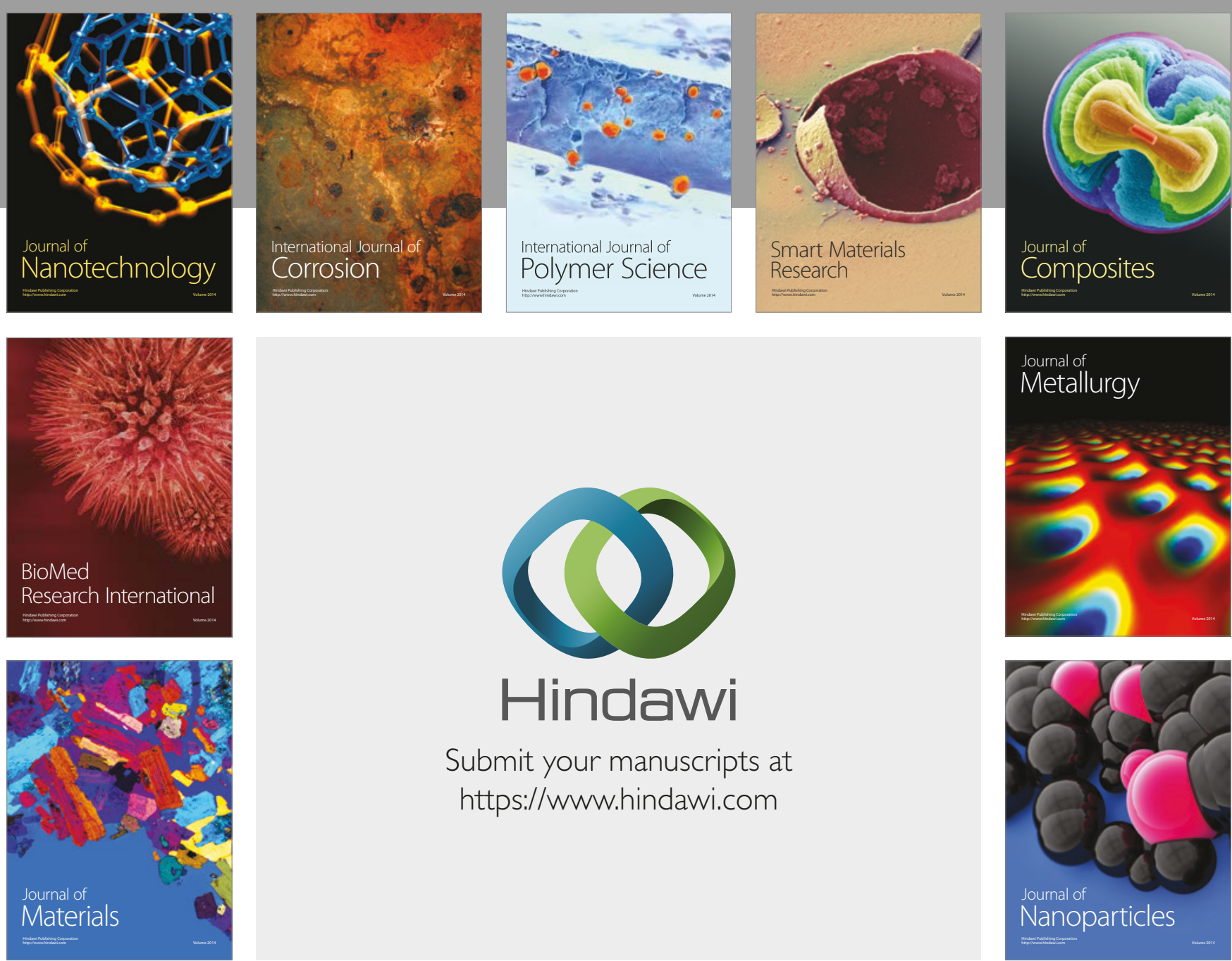

\section{Hindawi}

Submit your manuscripts at

https://www.hindawi.com
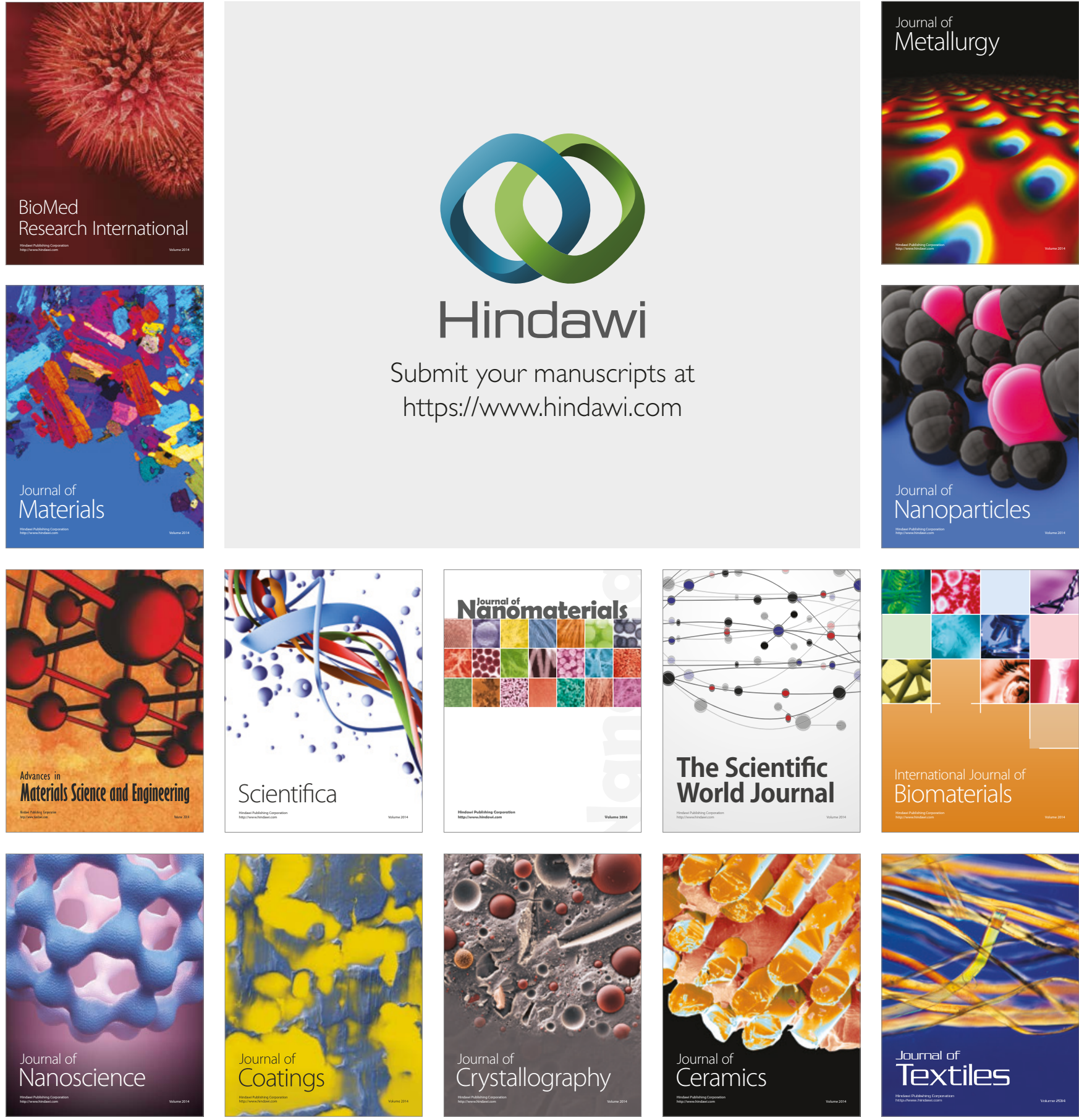

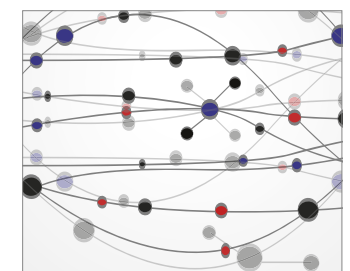

The Scientific World Journal
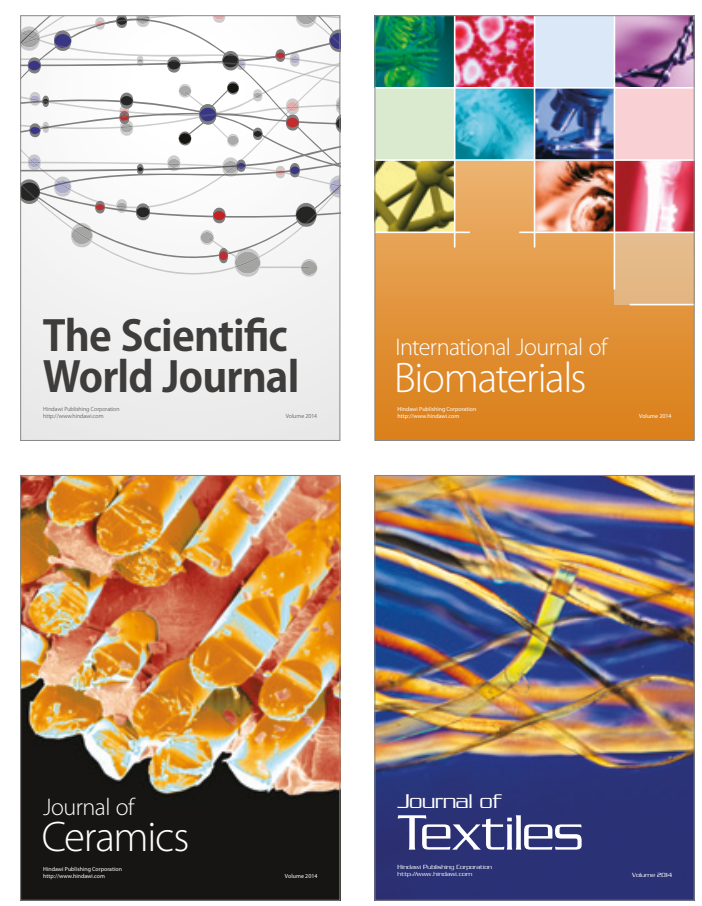